\title{
Representações Sociais e Ações Afirmativas: Estudantes Universitários e seus Posicionamentos
}

\author{
Representaciones Sociales y Acciones Afirmativas: Estudiantes Universitarios y sus \\ Posicionamientos
}

Social Representations and Affirmative Actions: University Students and Their Positions

\author{
Álvaro Rafael Santana Peixoto \\ ORCID: http://orcid.org/0000-0002-1480-7919 \\ Universidade do Estado do Rio de Janeiro - Rio de Janeiro/Brasil \\ Thamiris Marques da Silva \\ ORCID: http://orcid.org/0000-0003-3543-1444 \\ Universidade do Estado do Rio de Janeiro - Rio de Janeiro/Brasil \\ Rafael Moura Coelho Pecly Wolter \\ ORCID: http://orcid.org/0000-0003-1633-2141 \\ Universidade do Estado do Rio de Janeiro - Rio de Janeiro/Brasil
}

\section{RESUMO}

As políticas de ações afirmativas assumiram diversas formas em diferentes países, mas quase sempre ocasionaram debates e suscitaram posicionamentos diversos na sociedade. No Brasil esse tipo de política é marcado, principalmente, pelo sistema de cotas ou reserva de vagas em concursos e processos seletivos para determinadas minorias. Esse trabalho se enquadra dentro da psicologia social, tendo enfoque no campo teórico das representações sociais. Seu objetivo consiste em entender de que forma o pensamento social de estudantes cotistas e não cotistas se constituem em relação ao sistema de cotas para ingresso na universidade. Para alcançar esse objetivo foi aplicado um questionário, que continha questões em formato de evocação livre com o termo indutor "cotas" e questões em formato de itens de Likert com vistas a averiguar o posicionamento dos sujeitos em relação a diferentes tipos de cotas. Esse instrumento foi aplicado em 135 estudantes da Universidade do Estado do Rio de Janeiro, sendo 63 cotistas e 72 não cotistas. As análises desses dados foram feitas através das técnicas da análise prototípica e de similitude. Quando comparados, os grupos de cotistas e não cotistas, é possível notar acentuada diferença entre as suas representações sociais e seu campo atitudinal, o que pode justificar o aparecimento de argumentos diversos e contrários na sociedade sobre as cotas.

Palavras-chave: Cotas; Representações sociais; Campo atitudinal.

\section{RESUMEN}

Las políticas de acciones afirmativas asumieron diversas formas en diferentes países, pero casi siempre ocasionaron debates y suscitaron posicionamientos diversos en la sociedad. En Brasil ese tipo de política está marcado, principalmente, por el sistema de cuotas o reserva de vacantes en concursos y procesos selectivos para determinadas minorías. Este trabajo se encuadra dentro de la psicología social, teniendo enfoque en el campo teórico de las representaciones sociales. Su objetivo consiste en entender de qué forma el pensamiento social de estudiantes cotistas y no cotistas se constituyen en relación al sistema de cuotas para ingreso en la universidad. Para alcanzar ese objetivo fue aplicado un cuestionario, que contenía cuestiones en formato de evocación libre con el término inductor "cuotas" y cuestiones en formato de ítems de Likert con miras a averiguar el 
posicionamiento de los sujetos en relación a diferentes tipos de cuotas. Este instrumento fue aplicado en 135 estudiantes de la Universidad del Estado de Río de Janeiro, siendo 63 cotistas y 72 no cotistas. Los análisis de estos datos se realizaron a través de las técnicas del análisis prototípico y de similitud. Cuando se comparan, los grupos de cotistas y no cotistas, es posible notar acentuada diferencia entre sus representaciones sociales y su campo actitudinal, lo que puede justificar la aparición de argumentos diversos y contrarios en la sociedade sobre las cuotas.

Palabras clave: Cuotas; Representaciones sociales; Campo actitudinal.

\begin{abstract}
Affirmative action policies have assumed many forms in different countries, but have almost always caused debates and raised diverse positions in society. In Brazil, this type of policy is mainly marked by quota system or vacancies reservation in competitions and selective processes for certain minorities. This work fits within social psychology, focusing on the theoretical field of social representations. Its purpose is to understand how the social thinking of quota and non-quota students is related to the quota system for admission to university. In order to achieve this purpose, a questionnaire was used, which contained questions in a free evocation format with the term "quotas" and questions in the form of Likert items in order to ascertain the position of the subjects in relation to different types of quotas. This instrument was applied to 135 students of State University of Rio de Janeiro, among them 63 are quotaholders and 72 are non-quota holders. The analyzes of these data were made through the techniques of prototypical analysis and similitude analysis. The results show a accentuated difference of the social representations and the affective field when comparing the two groups, which may justify the emergence of diverse and contradictory arguments about quotas in society.
\end{abstract}

Keywords: Quotas; Social representations; Attitudinal field.

\section{Introdução}

A temática da meritocracia tem se tornado recorrente em diversos debates realizados na sociedade, sendo um conceito que é utilizado como insumo para diversos posicionamentos e justificativas. Valle (2013) demonstra que a meritocracia é vista por parte dos pesquisadores, políticos e administradores como uma possibilidade de diminuir as desigualdades sociais, já que a ela seria: "um princípio que harmoniza diferenças individuais e desigualdades sociais, promovendo o equilíbrio e a eficácia global da sociedade" (Valle, 2013, p. 10).

Valle e Ruschel (2009) demonstram a importância do tema da meritocracia para a sociedade ao afirmarem que o sistema ensino brasileiro, principalmente a partir da década de 1980, usou o conceito de meritocracia para definir políticas e práticas escolares e nesse contexto o papel da escola era: promover a integração social, desenvolver as potencialidades biopsíquicas dos indivíduos, reconhecer e valorizar seus méritos, formá-los moralmente e para o exercício da cidadania, prepará-los para o mercado de trabalho, mas também para a mobilização social, a organização e a participação política (Valle \& Ruschel, 2009, p. 195).

Valle (2013) demonstra que existem críticas ao conceito de meritocracia aplicado ao sistema educacional citando autores como Bolívar (2005), Dubet (2009) e Bourdieu (1989) para demonstrar que o sistema de ensino meritocrático, por vezes, não é neutro e possui a tendência de favorecer as classes mais privilegiadas da sociedade.

Outro ponto interessante que geralmente aparece nas discussões acerca da educação é a desigualdade social que no Brasil 
afeta o acesso das classes mais populares a serviços básicos da sociedade como a educação, a saúde, o saneamento básico e a segurança (Guzzo \& Euzébios Filho, 2005).

A desigualdade social afeta o acesso das classes baixas à educação básica como demonstra o trabalho de Guzzo e Euzébios Filho (2005), que apresenta dados de acesso ao ensino básico e coloca o sistema educacional como um reprodutor da divisão social do trabalho e um mantenedor das relações estabelecidas pelo capitalismo (Guzzo \& Euzébios Filho, 2005). O acesso ao ensino superior também é afetado pela desigualdade social, como demonstra Picanço (2015), que afirma que os negros e as classes populares possuem muito menos acesso à universidade do que os brancos e as classes mais ricas.

As políticas de ações afirmativas têm origem justamente como resultados desses debates acerca da desigualdade social e oportunidades de acesso à educação. A expressão "ações afirmativas" surge nos Estados Unidos na década de 1960 e esse tipo de política se espalhou pelo mundo chegando a países como África do Sul, Nigéria, Austrália, Argentina, Índia, Cuba, países da Europa Ocidental, dentre outros. Nesses diversos países as ações afirmativas assumiram diversas formas, como demonstra Moehlecke (2002):

a ação afirmativa assumiu formas como: ações voluntárias, de caráter obrigatório, ou uma estratégia mista; programas governamentais ou privados; leis e orientações a partir de decisões jurídicas ou agências de fomento e regulação. (p. 199).

Apesar de terem havidos discussões sobre o tema já na década de 60 no Brasil, é apenas nos anos 80 que serão formulados os primeiros instrumentos jurídicos que irão instaurar de fato as ações afirmativas no país (Moehlecke, 2002). Muito desse histórico das discussões sobre a necessidade de inclusão de determinados grupos minoritários no Brasil foi articulado pela pressão exercida pelos movimentos sociais de militância negra, que buscavam soluções para a diminuir a grande discrepância de oportunidades que eram oferecidas à população negra no país (Guimarães, 2003).

No geral, esse tipo de política consiste em processos de planejamento e execução que visam aumentar a representatividade e igualdade de condições de classes de sujeitos que foram histórica e socialmente excluídas. O objetivo das ações afirmativas é possibilitar que esses grupos excluídos possam acessar determinados equipamentos e oportunidades que devido a este contexto social de exclusão social não conseguem usufruir plenamente (Moehlecke, 2002).

Esses grupos de sujeitos que são excluídos de diversos âmbitos da sociedade sofrem com preconceitos, discriminações, são frequentemente estereotipados e marginalizados apenas por sua pertença a determinados grupos (Freire Filho, 2004). Esses grupos sociais excluídos são chamados de minorias sociais, já que estão colocados em posição de dominados na sociedade e a eles são delegadas condições inferiores de vida em relação aos grupos dominantes. É importante afirmar que o termo minoria não possui relação com o quantitativo de pessoas na sociedade, mas sim com a posição em que aquele grupo ocupa na estratificação social (Moscovici, 2011). As minorias sociais são marginalizadas e excluídas devido a características étnicas, raciais, de gênero, de vulnerabilidade social, opção religiosa, dentre outras (Moreno, 2009).

Uma das políticas que está inserida dentro das ações afirmativas é o sistema de cotas, que consiste no fato de destinar uma porcentagem de vagas de determinado concurso ou seleção para uma população específica. Moehlecke (2002) define o sistema de cotas como um "determinado número ou percentual a ser ocupado em área específica por grupo(s) definido(s), o que pode ocorrer de maneira proporcional ou não, e de forma mais ou menos flexível" (p.3). 
A implementação do sistema de cotas em concursos e vestibulares no Brasil gerou e ainda gera muitos debates e suscita tomadas de posição polarizadas de diferentes grupos sociais, fazendo com que existam muitos argumentos favoráveis e contrários à adoção desse sistema enquanto uma medida válida para a diminuição das desigualdades sociais sofridas pelas minorias sociais (Queiroz \& Santos, 2006; Marques \& Santos, 2015).

Uma das situações que mais gera polêmicas no que tange ao sistema de cotas é quando essa medida é aplicada na reserva de vagas no vestibular das instituições de ensino superior brasileiras. A Universidade do Estado do Rio de Janeiro (UERJ) figura como uma das instituições pioneiras na adoção de diversos tipos de cotas, por esse motivo os seus estudantes figuram como um dos grupos sociais abordados pelo instrumento desenvolvido pela pesquisa retratada nesse trabalho (Mendes Junior, 2014).

Como demonstra Moehlecke (2002), os grupos abarcados pelas cotas são diversos, como minorias étnico-raciais e mulheres. $\mathrm{Na}$ UERJ as cotas são voltadas à população negra, aos estudantes de escola pública, aos deficientes físicos, indígenas, filhos de policiais civis e militares, bombeiros, inspetores de segurança e de administração penitenciária que foram mortos em serviço ou ficaram inválidos permanentemente (Queiroz \& Santos, 2006).

Conforme dito, as discussões acerca do sistema de cotas geraram diversos argumentos contrários e favoráveis. Marques e Santos (2015) demonstram que alguns dos argumentos favoráveis ao sistema de cotas são: o sistema de cotas oportuniza o acesso de grupos socialmente excluídos a instituições que geralmente reproduzem a exclusão realizada na sociedade; a possibilidade de compensar processos históricos negativos que ocorreram com determinados grupos sociais e os posicionaram de maneira inferiorizada na hierarquia social, como é o caso da escravidão com a população negra; é necessário diminuir as desigualdades na sociedade e as cotas raciais seriam uma maneira válida de possibilitar uma sociedade mais justa e igualitária (Marques \& Santos, 2015).

Um dos argumentos contrários ao sistema de cotas se baseia na defesa da isonomia e da igualdade, baseada no artigo $5^{\circ}$ da constituição brasileira, afirmando todos são iguais e não deveriam ser tratados de forma diferenciada nos processos seletivos (Marques \& Santos, 2015). Há também argumentos contrários pautados na dificuldade de definir padrões que guiem a classificação de sujeitos por sua cor devido à miscigenação da sociedade brasileira (Frias, 2012). Marques e Santos (2015) também demonstram os seguintes argumentos contrários às cotas raciais: as cotas devem abranger somente as questões socioeconômicas; o critério racial não justifica a criação de cotas específicas para essa população; as cotas geram mais discriminação e inferiorizam os beneficiados dessas políticas; o passado dos negros não interfere na sua condição atual na sociedade.

A listagem dos argumentos favoráveis e contrários ao sistema de cotas ilustra que esse tema apresenta grande importância na sociedade, de modo que o senso comum já cria argumentações e concepções acerca desse objeto. Com isso, é possível pensar que as cotas se configuram como um possível objeto de representações sociais, justificando o uso desse referencial teórico para o estudo e entendimento de como determinados grupos sociais compreendem a questão das cotas raciais.

\section{Fundamentação teórica}

O campo de estudo das representações sociais teve seu surgimento na psicologia social europeia francesa, através da tese de doutorado do psicólogo romeno Serge Moscovici, datada de 1961. O conceito de representações sociais teve diversos influenciadores prévios, mas talvez o conceito mais próximo advém da sociologia de Émile Durkheim, através do conceito de representações coletivas. As representações coletivas de Durkheim têm como 
características uma perenidade ao longo da história e são originadas nas sociedades primitivas, enquanto que Moscovici pensa as representações sociais com uma flexibilidade maior e delega a este fenômeno uma pertença às sociedades contemporâneas (Sá, 2015).

Para Moscovici o conhecimento se divide em dois universos: o reificado e o consensual. O universo reificado se refere ao conhecimento produzido pelas academias científicas, que obedece a critérios, hierarquias e regras rígidas previamente definidas. Já no universo consensual o conhecimento se constrói no senso comum e não segue prérequisitos e regras rígidas (Moscovici, 2003). Para integrar o universo reificado e produzir conhecimento nele o sujeito deve antes passar por uma qualificação técnica e apenas após um longo processo de preparação conseguirá estar plenamente inserido no universo reificado. Já no caso do universo consensual $o$ conhecimento se constrói através da conversação entre indivíduos comuns no cotidiano. Entre esses dois universos existe uma clara cisão que irá separar os produtores de conhecimento nos dois campos (Moscovici, 2003).

Moscovici chamou o conhecimento que é produzido no universo consensual de Representações Sociais. Dentre as inúmeras definições que esse conceito recebeu, a mais conhecida é a de Denise Jodelet (1989) que define as Representações Sociais como a "forma de conhecimento, socialmente elaborada e partilhada, que tem um objetivo prático e concorre para a construção de uma realidade comum a um conjunto social" (Jodelet, 1989, p.36).

O conceito e o campo das representações sociais foram amplamente trabalhados por diversos autores da psicologia social europeia e posteriormente se ampliaram para o resto do mundo, derivando-se em outras teorias e em diversas abordagens. Jean-Claude Abric é um dos autores que trabalhou o conceito e lançou um olhar estruturalista para as representações sociais. Abric (1994) e seus colaboradores da escola do Midi (Guimelli,
1994; Flament, 1994; Moliner, 1989) elaboraram a Teoria do Núcleo Central, a principal da abordagem estrutural, que irá definir as representações sociais como um saber estruturado a partir de um Núcleo Central e uma Periferia (Sá, 2002).

O núcleo central confere significado às representações sociais e nele estão contidas as relações que o grupo possui com o objeto representado e a natureza desse objeto. Uma das facetas do núcleo central é a de organizar a representação, determinando a forma como os elementos que a constituem se relacionam e conferindo a ela uma estabilidade. Outra função do núcleo é a de gerador, já que também produz o valor e o significado dos elementos constituintes das representações sociais. É no núcleo central que estão contido os elementos essenciais da representação social, sem eles ela se descaracterizaria por completo. O núcleo central é pouco suscetível a mudanças por influências externas, se configurando de maneira inflexível e estável e garantindo que a representação perdure sem perder seus elementos fundamentais (Sá, 2002).

O sistema periférico é o outro componente estrutural que forma a representação social em conjunto com o núcleo central, nele estão contidos elementos mais singulares e contingenciais da representação. A periferia é uma estrutura muito mais flexível e mais adaptável a mudanças externas, já que a modificação dos elementos presentes na periferia não descaracterizaria de maneira fundamental a representação social de determinado objeto. Uma das funções do sistema periférico é defender a representação social, absorvendo elementos externos que podem afetar e colocar em risco o núcleo central. Outra função exercida pela periferia é a de concretização, que transforma em concreta uma representação que ainda está em estágio abstrato. Por fim, essa estrutura periférica exerce a função reguladora, adaptando os elementos representacionais de maneira a permitir que haja uma coerência entre a 
representação social e a realidade (Abric, 1994).

Com base na teoria das representações sociais, com enfoque na abordagem estrutural desta teoria, esse estudo pretende entender melhor de que modo se constituem as representações sociais de estudantes contrários e favoráveis às cotas raciais. Para isso, pretende-se compreender quais cognemas são candidatos a integrar o núcleo central e o sistema periférico da representação social acerca das cotas.

\section{Método}

Os sujeitos envolvidos neste estudo foram 135 estudantes da UERJ provenientes de diferentes cursos dessa universidade, dentre eles 63 eram cotistas (19 homens, 44 mulheres) com uma idade média de 21,23 anos $(\mathrm{DP}=2,8)$ e $72 \quad(33$ homens e 39 mulheres) participantes entraram na universidade pela modalidade de ampla concorrência com idade média de 23,10 $(\mathrm{DP}=5,01)$. Conforme retratado na introdução deste artigo, a UERJ figura como uma das universidades pioneiras a adotar o sistema de cotas em seu vestibular e por esse motivo se configura como um contexto propício à realização desse tipo de estudo. Os participantes foram recrutados nos corredores dos diferentes cursos do campus Maracanã da UERJ de maneira que a aleatoriedade na escolha dos sujeitos ajude a não causar um desequilíbrio nas respostas. As aplicações eram feitas de maneira individual com acompanhamento de um pesquisador dentro das dependências da própria UERJ.

A coleta de dados foi composta por um instrumento com tarefas de evocações livres, que possuíam o termo indutor "cotas". Essa técnica se baseia em pedir ao sujeito que escreva ou cite as primeiras palavras que lhe vem à cabeça quando leem ou ouvem determinado termo indutor, que no caso deste trabalho é o termo "cotas". Essa técnica tem como objetivo explicitar quais ideias possivelmente integram o núcleo central e a periferia da representação social de determinado objeto social. Nesse trabalho, conforme já foi dito, o termo indutor da evocação livre é "cota" e são solicitados os cinco primeiros termos ou frases que primeiro surgem na cabeça do sujeito quando apresentado ao tema (Oliveira, Marques, Gomes, Teixeira, \& Amaral, 2005; Vergès \& Guimelli, 1994).

O questionário contava ainda com questões em formato de itens de Likert que visavam medir o posicionamento do grupo de estudantes cotistas e não cotistas em relação às cotas para negros, para indígenas e para estudantes de escola pública. As questões de Likert consistem em apresentar uma afirmação ou conceito para o sujeito, que deve marcar dentre algumas opções se concorda ou discorda da afirmação ou se é contrário ou favorável do conceito apresentado. A escala de Likert geralmente apresenta de 5 a 7 opções de marcação para o sujeito, que geralmente vai de "Discordo Totalmente" até "Concordo Totalmente" (Likert, 1932).

Para a análise das evocações livres foi utilizada a análise prototípica que também é conhecida como análise das quatro casas, onde é realizada uma análise dos termos evocados de forma a calcular a frequência com que as evocações surgem bem como a ordem com que aparecem. Os elementos do núcleo central são os que aparecem com mais frequência e em uma ordem mais imediata; os elementos que surgem com maior frequência mas de maneira menos imediata são os que constituem os elementos da periferia; Os elementos evocados em ordem mais imediata mas com menos frequência de aparição formam a chamada zona de contraste; por último, os elementos que compõe a chamada segunda periferia, são aqueles evocados com menor frequência e com ordem menos imediata de aparição (Vergès, 1992; Wachelke \& Wolter, 2011). Com as evocações livres também foram realizadas análises de similitude, esta análise calcula as relações entre termos evocados e foi aqui apresentada em formato de uma árvore máxima. Existem diferentes formas de se calcular a relação entre os elementos na análise de similitude, nesta 
pesquisa foi utilizado o índice de Jaccard, por vezes chamado de índice de comunidade, que leva em conta a proporção da intersecção entre os dois elementos sobre o total de aparições (Wolter \& Wachelke, 2013).

Essas técnicas de análise utilizadas em dados colhidos pela técnica de evocação livre não são suficientes para determinar de forma categórica o núcleo central e o sistema periférico de uma representação social. Essas

técnicas podem apenas indicar os elementos que são candidatos a integrar a periferia e o núcleo central, possibilitando um primeiro contato com a representação social. Existem técnicas mais robustas como a de Esquemas Cognitivos de Base (Wolter, Wachelke \& Naiff), que são utilizadas para determinar, de fato, quais elementos compõem a periferia e o núcleo central da representação social.

\section{Resultados}

Tabela 1

Análise prototípica da evocação livre de estudantes cotistas da UERJ frente ao termo indutor "Cotas"

\begin{tabular}{|c|c|c|c|c|c|c|c|}
\hline \multicolumn{8}{|c|}{ Ordem média de evocação $(O M E) \leq 2,57$} \\
\hline \multirow{9}{*}{$\begin{array}{c}\text { Frequência } \\
\leq 6\end{array}$} & \multicolumn{4}{|c|}{-} & \multicolumn{3}{|c|}{+} \\
\hline & \multirow{4}{*}{+} & & OME & $\mathrm{F}$ & & OME & $\mathrm{F}$ \\
\hline & & Igualdade & 2,21 & 23 & Direito & 2,92 & 13 \\
\hline & & Oportunidade & 2,13 & 23 & Justiça & 2,58 & 12 \\
\hline & & Reparação & 1,90 & 10 & Inclusão & 2,62 & 8 \\
\hline & & Política & 2,57 & 7 & Desigualdade & 3,00 & 6 \\
\hline & & Necessário & 2,33 & 6 & Preconceito & 3,66 & 6 \\
\hline & - & Racismo & 2,33 & 6 & Paliativo & 3,60 & 5 \\
\hline & & Negro & 1,20 & 5 & & & \\
\hline
\end{tabular}

Nota. Fonte: Recuperado de "Pensamento social, justiça e cotas: um estudo de representações sociais com universitários", de T. Marques, 2016, Dissertação de mestrado, Universidade do Estado do Rio de Janeiro (UERJ), Rio de Janeiro, Brasil.

A Tabela 1 apresenta as evocações de alunos cotistas da UERJ quando são apresentados ao termo "cotas". Segundo a análise prototípica os prováveis candidatos ao núcleo central da representação social desse grupo acerca das cotas são formados pelas evocações: "igualdade", "oportunidade" e "reparação", já que são os termos evocados de maneira mais imediata e frequente.

A estrutura da primeira periferia dessa representação seria formada pelos termos "direito" e "justiça" e fechando a estrutura da representação, as evocações "desigualdade", "preconceito" e "paliativo" formam a segunda periferia. Os termos "política", "necessário", "racismo" e "negro" formam a zona de contraste.

Os cotistas formulam sua representação acerca do termo indutor "cotas" de maneira a pensar essa política enquanto um processo necessário e uma medida de reparação às injustiças e faltas de oportunidade ocasionadas pelo racismo e pelo preconceito que afetam a população negra de maneira mais incisiva.

A Tabela 2 demonstra, através da análise prototípica, a forma como o grupo de não cotistas da UERJ formula a estrutura de sua representação social acerca das cotas. O núcleo central dessa representação é possivelmente formulado pelas evocações: "negro", "igualdade", "desigualdade" e "oportunidade".

Na primeira periferia estão presentes os termos "justiça" e "direito", enquanto a segunda periferia conta com os termos "educação", "pobre", "preconceito" e "bolsa". Já a zona de contraste contém as evocações "inclusão", "necessário", “ajuda" e "discriminação". 
Tabela 2

Análise prototípica da evocação livre de estudantes não cotistas da UERJ frente ao termo indutor "Cotas"

\begin{tabular}{|c|c|c|c|c|c|c|c|}
\hline \multicolumn{8}{|c|}{ Ordem média de evocação $(O M E) \leq 2,68$} \\
\hline \multirow{10}{*}{$\begin{array}{l}\text { Frequência } \\
\quad \leq 10\end{array}$} & \multicolumn{4}{|c|}{-} & \multicolumn{3}{|c|}{+} \\
\hline & \multirow{5}{*}{+} & & OME & $\mathrm{F}$ & & OME & $\mathrm{F}$ \\
\hline & & Igualdade & 2,68 & 16 & Direito & 2,92 & 13 \\
\hline & & Negro & 2,06 & 16 & Justiça & 2,58 & 12 \\
\hline & & Desigualdade & 2,18 & 11 & & & \\
\hline & & Oportunidade & 2,27 & 11 & & & \\
\hline & & Inclusão & 2,60 & 10 & Educação & 2,85 & 7 \\
\hline & & Necessário & 2,55 & 9 & Pobre & 3,00 & 7 \\
\hline & - & Ajuda & 2,28 & 7 & Preconceito & 3,20 & 5 \\
\hline & & Discriminação & 2,66 & 6 & Bolsa & 3,20 & 5 \\
\hline
\end{tabular}

Nota. Fonte: Recuperado de "Pensamento social, justiça e cotas: um estudo de representações sociais com universitários", de T. Marques, 2016, Dissertação de mestrado, Universidade do Estado do Rio de Janeiro (UERJ), Rio de Janeiro, Brasil.

Quando observadas e comparadas as Tabelas 1 e 2 é possível notar que "igualdade" e "oportunidade" são termos comuns ao núcleo central da representação social dos dois grupos, enquanto que os termos "negro" e "desigualdade" aparecem de maneira mais relevante no grupo de não cotistas.

A observação desses dois elementos é importante, já que a presença do termo "negro" na representação do grupo de não cotistas denota que, para este grupo, as cotas são mais comumente relacionadas a esta minoria específica mesmo sendo uma política que abarca outros grupos minoritários na sociedade. Já o termo central "desigualdade", que aparece de maneira concomitante com a evocação "igualdade", parece demonstrar que para o grupo de estudantes não cotista as cotas são um meio de se diminuir a desigualdade na sociedade.

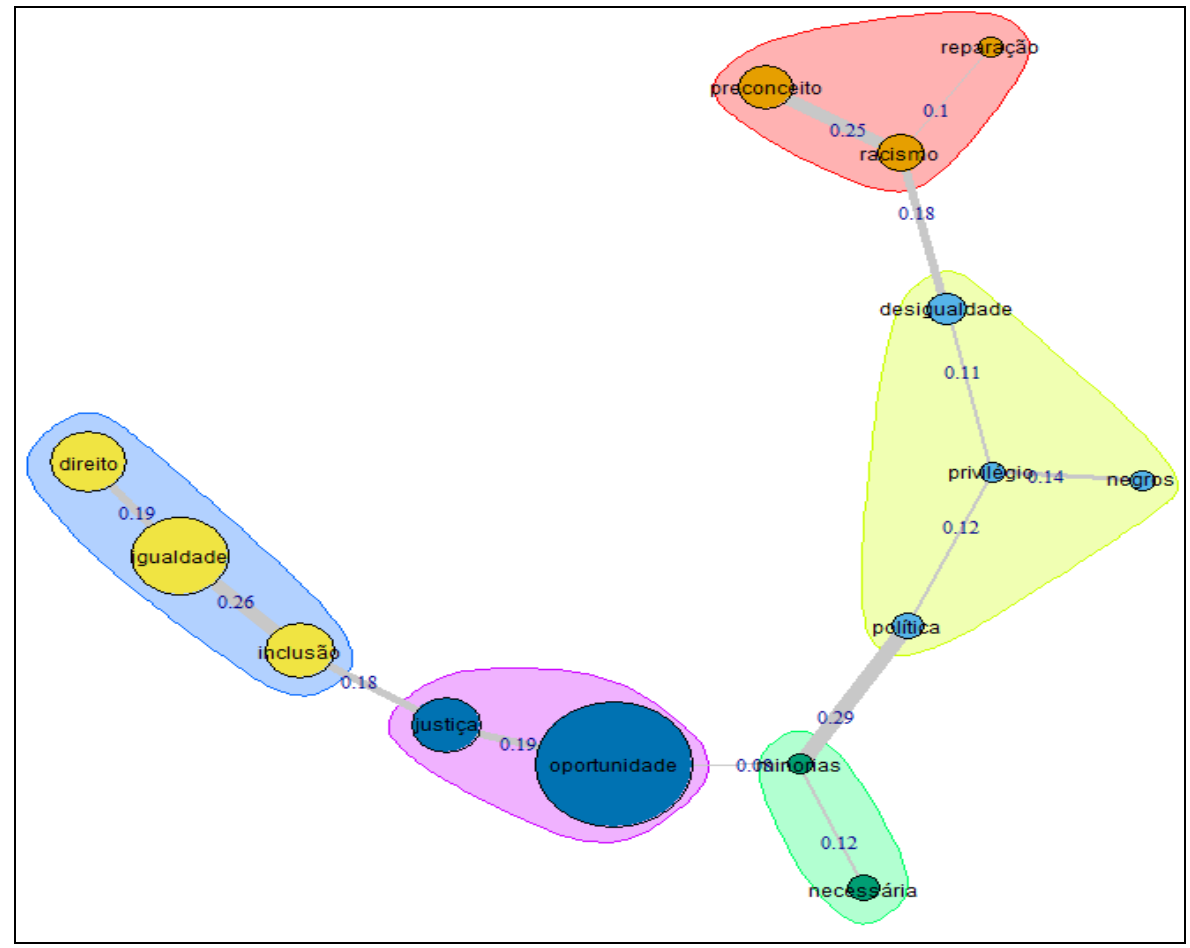

Figura 1. Análise de similitude dos elementos da representação social das cotas em estudantes cotistas da UERJ

Fonte: Recuperado de "Pensamento social, justiça e cotas: um estudo de representações sociais com universitários", de T. Marques, 2016, Dissertação de mestrado, Universidade do Estado do Rio de Janeiro (UERJ), Rio de Janeiro, Brasil. 
$\mathrm{Na}$ Figura 1 são apresentadas as evocações dos estudantes cotistas da UERJ segundo análise de similitude. Aqui é possível observar que os termos "direito", "igualdade" e "inclusão" estão conectados entre si e transmitem a ideia de que através das cotas são possibilitadas maiores oportunidades aos grupos minoritários que são assistidos por este tipo de política. É possível notar, pela associação dos termos "racismo", "preconceito" e "reparação", que os cotistas pensam nas cotas como uma forma de reparação ao racismo e preconceito sofridos pelos grupos minoritários. A associação dos termos "oportunidade" e "justiça" demonstram que esse grupo pensa nas cotas como uma oportunidade de promoção de justiça aos grupos minoritários.

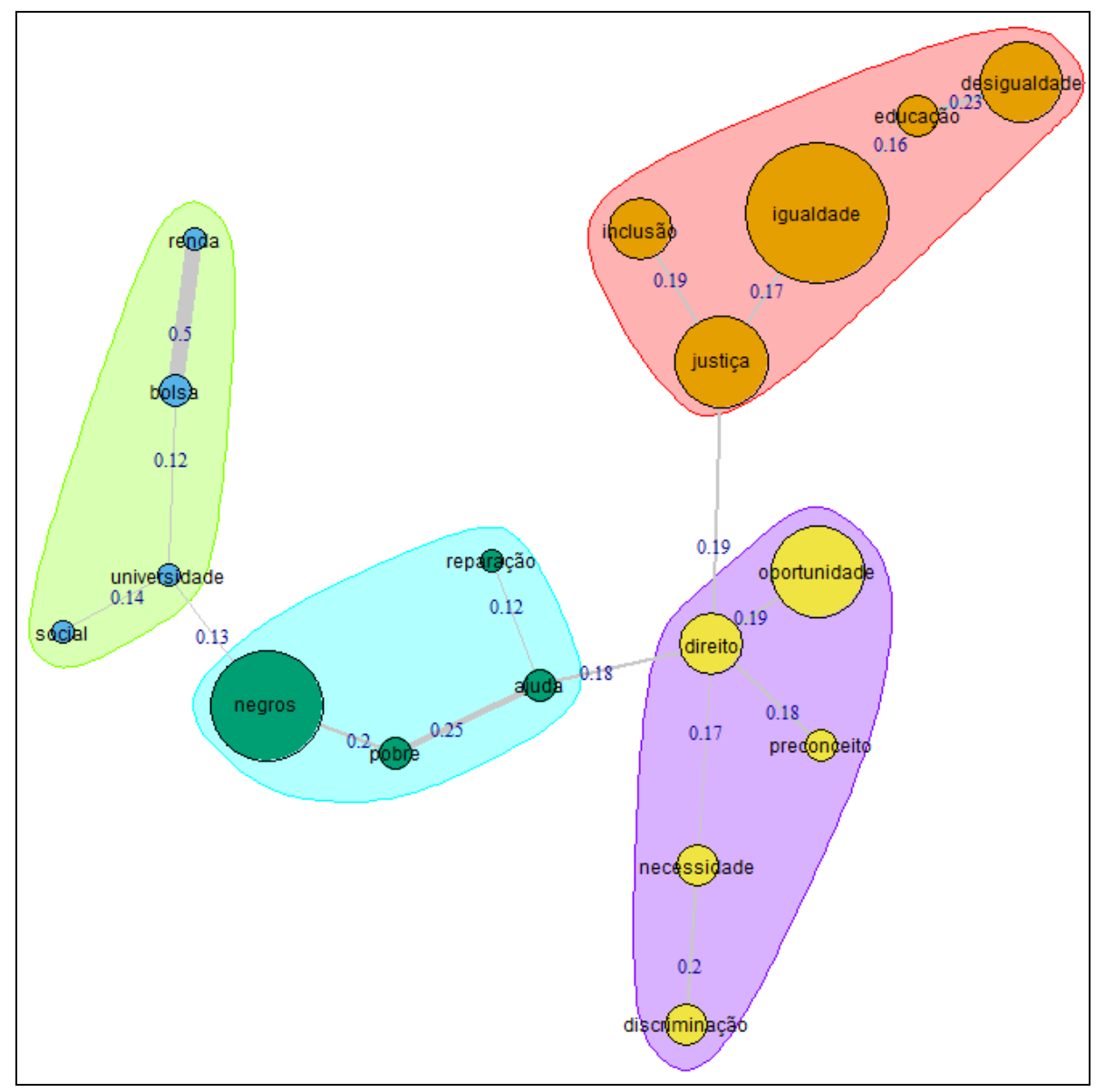

Figura 2. Análise de similitude dos elementos da representação social das cotas em estudantes não cotistas da UERJ

Fonte: Recuperado de "Pensamento social, justiça e cotas: um estudo de representações sociais com universitários", de T. Marques, 2016, Dissertação de mestrado, Universidade do Estado do Rio de Janeiro (UERJ), Rio de Janeiro, Brasil.

Os dados da Figura 2 apresentam a análise de similitude das evocações de estudantes não cotistas sobre as cotas. Os termos "desigualdade" e "igualdade" são relevantes nessa representação e parecem colocar as cotas no cerne na discussão sobre desigualdade de oportunidades de acesso à educação. A presença desses termos pode estar conectada a um dos principais argumentos contrários às cotas, que consiste em dizer que esse sistema interferiria no princípio de igualdade presente na constituição brasileira.

Quando comparadas as análises de similitude dos dois grupos é possível notar que o termo "negro" surge com maior importância no grupo de não cotistas estando ligado a fatores de compensação econômica. Já no grupo de cotistas a questão da reparação histórica surge como fator mais relevante, podendo indicar que esse grupo pensa as cotas 
como um fator de reparação de processos sócio históricos que ainda prejudicam as minorias.

Enquanto a análise prototípica ajuda a identificar os candidatos ao núcleo central e ao sistema periférico das representações sociais, a análise de similitude ajuda a compreender de que forma essas ideias se relacionam. Dessa maneira é possível compreender de que forma os grupos de estudantes cotistas e não cotistas criam teorias e lidam com o sistema de cotas.

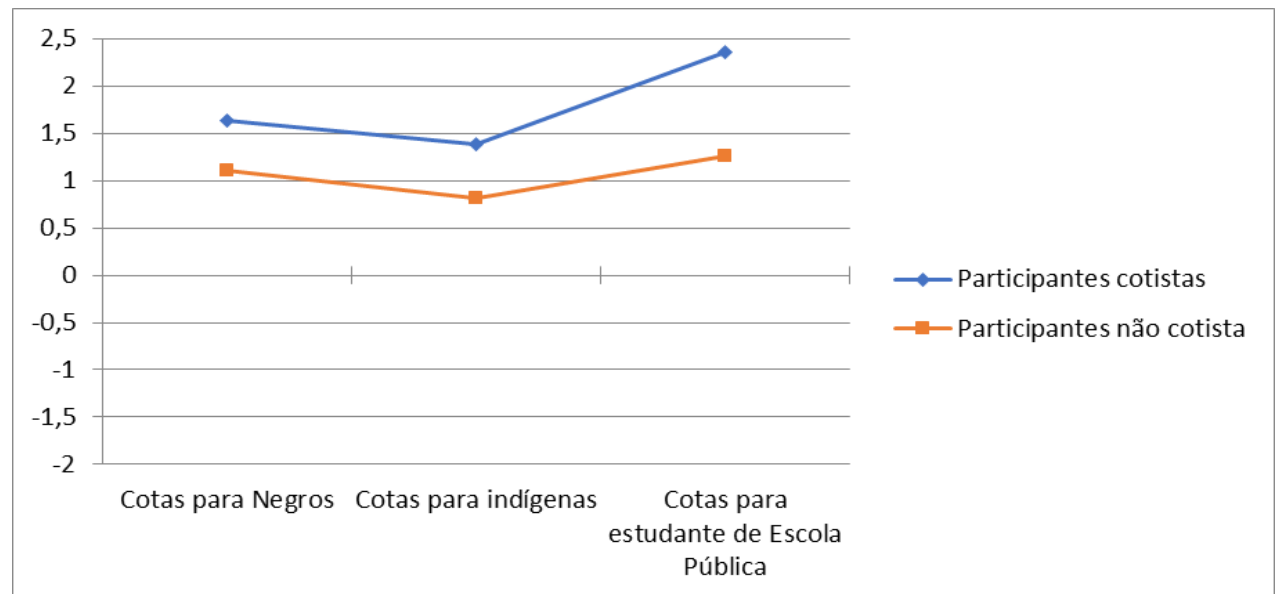

Figura 3. Posicionamento de cotistas e não cotistas em relação às cotas para negros, para indígenas e estudantes de escola pública que possuem como critério a renda do sujeito Fonte: Recuperado de "Pensamento social, justiça e cotas: um estudo de representações sociais com universitários", de T. Marques, 2016, Dissertação de mestrado, Universidade do Estado do Rio de Janeiro (UERJ), Rio de Janeiro, Brasil.

A figura 3 apresenta os posicionamentos de estudantes cotistas e não cotistas com relação a cotas para negros, para indígenas e para estudantes de escola pública onde são levadas as condições financeiras dos sujeitos em consideração. Os dados demonstram que o posicionamento de estudantes cotistas é sempre mais favorável a todos os tipos de cotas do que o posicionamento dos estudantes não cotistas. Também é possível observar que os grupos apresentam um posicionamento menos favorável em relação às cotas para indígenas quando comparadas às outras modalidades de cotas. Já as cotas para estudantes de escola públicas angariam o posicionamento mais favorável dos dois grupos.

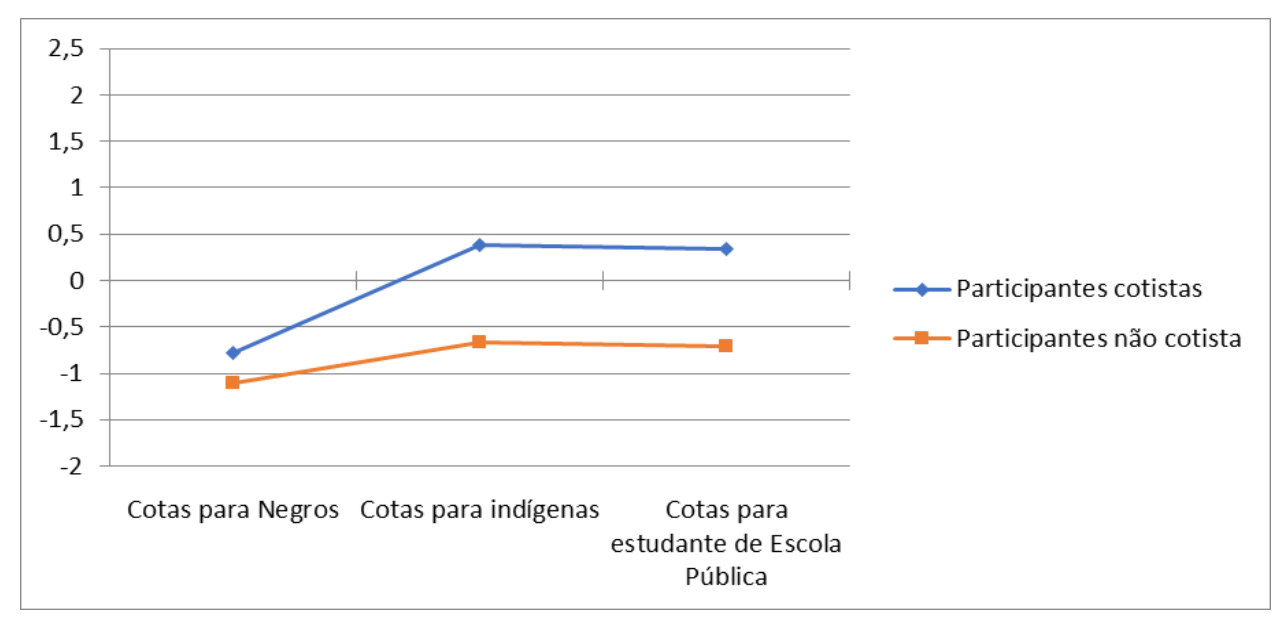

Figura 4. Posicionamento de cotistas e não cotistas em relação às cotas para negros, para indígenas e estudantes de escola pública que não possuem como critério a renda do sujeito

Fonte: Recuperado de "Pensamento social, justiça e cotas: um estudo de representações sociais com universitários", de T. Marques, 2016, Dissertação de mestrado, Universidade do Estado do Rio de Janeiro (UERJ), Rio de Janeiro, Brasil. 
A figura 4 apresenta os posicionamentos de grupos de estudantes cotistas e não cotistas acerca das cotas para negros, para indígenas e para estudantes de escola pública que não levam em conta as condições financeiras dos indivíduos como critério de atribuição. É possível notar uma acentuada rejeição dos dois grupos com relação às cotas para negros, com uma leve rejeição maior do grupo de não cotistas. Também é possível notar que o grupo de participantes não cotistas possui um posicionamento contrário com relação às outras duas modalidades de cotas, enquanto que o grupo de participantes cotistas possui um posicionamento favorável em relação a estes dois tipos de cotas.

É possível observar que ambos os grupos apresentam uma diferença significativa quando é alterada a condição de considerar a renda ou não para atribuir a cota, de maneira que quando a renda é levada em conta o posicionamento dos grupos se mostra muito mais favorável a todas as modalidades de cotas do que quando esse critério não é utilizado, isso ocorre com todos os tipos de cotas e com os dois grupos estudados. Também é possível perceber que as cotas para negros ocasionam posicionamentos mais contrários do que os demais tipos de cotas e isso acontece tanto no grupo de cotistas quanto no grupo de não cotistas.

Os dados demonstram que tanto as representações sociais quanto o posicionamento acerca das cotas e das cotas raciais possuem marcadas diferenças quando se observam os grupos de estudantes cotistas e o grupo de estudantes não cotistas. $O$ grupo de cotistas possuem um posicionamento, no geral, mais positivo do que os não cotistas e sua representação social das cotas consideram elementos diferentes para serem constituídas.

\section{Discussão}

O sistema de cotas, principalmente as cotas raciais voltadas para a população negra, gera argumentos diversos e antagônicos na sociedade brasileira. Esse trabalho pretendeu observar como esse objeto social se estrutura no pensamento social de estudantes cotistas e não cotistas da UERJ, que lidam com a realidade desse tema em seu dia a dia.

Ao observar os resultados apresentados é possível notar diferenças nas representações sociais de estudantes cotistas e não cotistas como: a presença dos termos "negro" e desigualdade" como possíveis candidatos ao núcleo central das representações sociais dos estudantes não cotistas. Já como candidatos ao núcleo central das representações sociais de estudantes cotistas encontram-se o termo "reparação", enquanto que o termo negro aparece apenas na periferia.

Esses fatores podem significar que quando os estudantes não cotistas pensam as cotas o termo "negro" é uma ideia central, de modo que esse grupo não consegue pensar cotas sem considerar a sua modalidade voltada à população negra. O termo "negro" está diretamente ligado ao termo "privilégio" parecendo demonstrar que o grupo de não cotistas tende a pensar as cotas, principalmente as raciais, enquanto ocasionadoras de um privilégio para a população negra.

O termo "desigualdade", presente no núcleo central no grupo de estudantes não cotistas, parece demonstrar que as cotas são necessárias enquanto existir uma desigualdade no sistema educacional, já que está intimamente ligado ao termo "educação". Essa configuração de elementos parece validar o sistema de cotas, para o grupo de não cotistas, enquanto uma possibilidade de reduzir desigualdades presentes na educação.

Esses dois fatores, o termo "negro" ligado ao termo "privilégio" e o termo "desigualdade" ligado ao termo "educação", podem explicar as diferenças entre os dois grupos no que tange a seu posicionamento acerca do sistema de cotas, já que o grupo de não cotistas se posiciona a favor desse sistema quando são levadas em consideração as condições econômicas dos sujeitos e são 
contrários quando as condições econômicas não são levadas em consideração.

Já a presença do termo "reparação" como possível integrante do núcleo central da representação dos estudantes cotistas parece validar e gerar, para esse grupo, o argumento de que algumas minorias devem ser recompensadas por processos sócio histórico que as prejudicaram. Isso pode ser corroborado pelo aparecimento do termo "racismo" na representação, demonstrando que para o grupo de cotistas as cotas podem auxiliar no combate e na diminuição do racismo, enquanto que para os não cotistas o foco das cotas parece ser diminuir as desigualdades promovidas pelo sistema educacional.

Essas diferenças entre os dois grupos não se encerram no campo representacional $\mathrm{e}$ também seguem no campo atitudinal, como observado nos posicionamentos dos grupos acerca do sistema de cotas. O grupo de cotistas possui um posicionamento significativamente mais favorável às diferentes modalidades de cotas do que o grupo de não cotistas.

Outro fato claramente observável com a análise de dados é o fato de que as cotas universitárias voltadas à população negra geram maiores posicionamentos contrários do que as outras modalidades de cotas. Esse fato fica ainda mais acentuado quando a cota não considera fatores sociais para ser atribuída, fato que acentua um posicionamento contrário em todas as modalidades de cotas, mas com uma maior influência nas cotas para negros.

Os dados das representações sociais e dos campos atitudinais conversam e se relacionam, tendo em vista que as representações sociais estão diretamente ligadas ao campo das atitudes. Isso faz com que o conhecimento construído de maneira social influência e gere de maneira direta a forma como um grupo irá se posicionar frente a um objeto social. Esse fato fica claro quando se observa a Arquitetura do Pensamento Social formulada por Michel-Louis Rouquette que formula o pensamento social enquanto uma hierarquia de estruturas. Nessa hierarquia as representações sociais estão colocadas de maneira imediatamente acima das atitudes, gerindo esse campo afetivo. Desta maneira as diferenças observadas nas representações sociais dos estudantes cotistas e não cotistas explicam posicionamentos diferenciados em relação ao sistema de cotas (Wolter \& Gurrieri \& Sorribas, 2009).

Dentro da Arquitetura do Pensamento Social de Rouquette as atitudes estão posicionadas logo acima das opiniões, de modo que na geração de argumentos sobre determinado objeto social será levado em conta o posicionamento frente a este objeto. Esse fator pode explicar a geração de argumentos contrários diversificados sobre o sistema de cotas e sobre as cotas raciais no campo social e na universidade entre os estudantes, que são o foco deste trabalho (Wolter \& Gurrieri \& Sorribas, 2009).

$\begin{array}{clcc}\text { Outro } & \text { fator que } & \text { explica } \\ \text { posicionamentos } & \text { e representações } & \text { sociais }\end{array}$ diferentes frente ao objeto cotas dos grupos de estudantes cotistas e não cotistas é a relação que eles possuem com o objeto. Os estudantes cotistas por fazerem uso desse sistema e possuírem uma relação mais próxima com ele desenvolvem elementos diferentes e tendem a ativar elementos mais funcionais da representação, conforme demonstra Abric (2003).

Já os estudantes não cotistas não chegam a estar distantes do objeto cotas, já que se relacionam em seu dia a dia com esse objeto na universidade e se relacionaram no vestibular para a entrada na universidade, mas claramente possuem uma relação diferenciada das estudantes cotistas. Os estudantes não cotistas não possuem necessidade de realizar procedimentos práticos em relação as cotas como o preenchimento de atestados e documentos, o recebimento de bolsas, dentre outras atividades, o que pode ocasionar a ativação mais frequente de elementos normativos em detrimento de elementos funcionais (Abric, 2003). 
É possível notar que a relação diferenciada com o objeto cotas e a condição de cotista ou não, influencia a forma como os grupos desenvolvem sua representação social acerca do objeto. As representações sociais das cotas influenciam diretamente os posicionamentos desses grupos. Fechando o efeito dominó, o campo afetivo influencia diretamente na geração de opiniões e argumentos sobre o tema.
Por fim, é possível notar que o campo teórico das representações sociais auxilia na compreensão de como os diferentes grupos sociais se relacionam e posicionam em relação ao objeto cotas. Compreender esse objeto e suas relações com instituições e grupos é fundamental para a formulação, fortalecimento e reformulação desse sistema e das políticas de ação afirmativa como um todo.

\section{Referências}

Abric, J. C. (1994). Pratiques Sociales et Representations. Paris: Presses Universitaires de France.

Abric, J. C. (2003). A abordagem estrutural das representações sociais: desenvolvimentos recentes. In P. H. F. Campos \& M. C. S. Loureiro, (orgs.), Representações sociais e práticas educativas (pp. 37-57). Goiânia: Ed. UCG.

Bolívar, A. (2005). Equidad educativa y teorías de la justicia. REICE - Revista Electrónica Iberoamericana sobre Calidad, Eficacia y Cambio en Educación, 3(2), 129. Recuperado de http://www.redalyc.org/pdf/551/55103205. pdf.

Bourdieu, P. (1989). La noblesse d'État: grandes écoles et esprit de corps. Paris: Minuit.

Dubet, F. (2009). Le travail des sociétés. Paris: Seuil.

Flament, C. (1994). Structure, dynamique et transformation des représentations sociales. In J. C. Abric, (Ed.), Pratiques sociales et representations (pp. 37-57). Paris, PUF.

Freire Filho, J. (2004). Mídia, Estereótipo e Representação das Minorias. ECO-PÓS, 7 (2), 45-71. Recuperado de https://revistas.ufrj.br/index.php/eco_pos/ar ticle/view/1120/1061.

Frias, L. (2012). As cotas raciais e sociais em universidades públicas são injustas? Direito, Estado e Sociedade, 41, 130-156. Recuperado de http://www.jur.pucrio.br/revistades/index.php/revistades/articl e/viewFile/157/142.
Guimarães, A. S. A. (2003). Acesso de negro às Universidades Públicas. Cadernos de Pesquisa, 118, 247-268. Recuperado de http://www.scielo.br/pdf/cp/n118/16836.pd f.

Guimelli, C. (1994). Structures et transformations des représentations sociales. França : Delachaux et Niestlé.

Guzzo, R. S. L. \& Euzébios Filho, A. (2005). Desigualdade social e sistema educacional brasileiro: a urgência da educação emancipadora. Escritos sobre Educação, 4(2), 39-48. Recuperado de http://pepsic.bvsalud.org/scielo.php?script= sci_arttext\&pid=S167798432005000200005 .

Jodelet, D. (1989). Représentations sociales: un domaine en expansion. Paris: PUF.

Mendes Junior, A. A. F. (2014). Uma análise da progressão dos alunos cotistas sob a primeira ação afirmativa brasileira no ensino superior: o caso da Universidade XX. Ensaio: Avaliação e Políticas Públicas em Educação, 22(82), 31-56. Recuperado de

http://www.scielo.br/pdf/ensaio/v22n82/a0 3v22n82.pdf.

Likert, R. (1932). A technique for the measurement of attitudes. Archives of Psychology. 140, 44-53. Recuperado de https://legacy.voteview.com/pdf/Likert 193 2.pdf.

Marques, T., \& Santos, B. K. A. (2015). Um estudo sobre o pensamento social de jovens universitários acerca da justiça e das cotas raciais. Revista Psicologia \& Saber Social, 
4 (1), 108-125.

doi:10.12957/psi.saber.soc.2015.17559.

Marques, T. (2016). Pensamento social, justiça e cotas: um estudo de representações sociais com universitários (Disertação de mestrado). Universidade do Estado do Rio de Janeiro-UERJ, Rio de Janeiro, RJ, Brasil.

Moehlecke, S. (2002). Ação afirmativa: história e debates no Brasil. Cadernos de Pesquisa, 117, 197-218. doi:10.1590/S0100-15742002000300011.

Moliner, P. (1989). Validation expérimentale de l'hypothèse du noyau central des représentations sociales. Bulletin de Psychologie, (42), 759-762.

Moreno, J. P. (2009). Conceito de minorias e discriminação. Revista USCS , 10 (17), 141-156. Recuperado de http://seer.uscs.edu.br/index.php/revista_dir eito/article/view/888.

Moscovici, S. (2003). Representações sociais: investigações em psicologia social. Rio de Janeiro: Vozes.

Moscovici, S. (2011). Psicologia das minorias ativas. Petrópolis, RJ: Vozes.

Oliveira, D. C., Marques, S. C., Gomes, A. M. T., Teixeira, M. C. T. V., \& Amaral, M. A. D. (2005). Análise das evocações livres: uma técnica de análise estrutural das representações sociais. In A.S.P. Moreira, B. V. Camargo, J. C. Jesuíno, \& M. Nóbrega (Orgs.). Perspectivas teóricometodológicas em representações sociais (pp.573-603). João Pessoa: Editora Universitária da UFPB.

Picanço, F. (2015). Juventude por cor e renda no acesso ao ensino superior: somando desvantagens, multiplicando desigualdades?. Revista Brasileira de Ciências Sociais, 30 (88), 145-181. doi:10.17666/3088145-179/2015.

Queiroz, D. M. \& Santos, J. T. (2006).

Sistema de cotas: um debate. Dos dados à manutenção de privilégios e de poder. Educ. Soc., 27 (96). doi: $\underline{\mathrm{S} 0101-}$ 73302006000300005

Sá, C. P. (2002). A teoria do núcleo central das representações sociais. In C. P. Sá
(Org.). Núcleo central das representações sociais (pp. 51-98). Petrópolis: Vozes.

Sá, C. P. (2015). Estudos de Psicologia social. Rio de Janeiro: Eduerj.

Valle, I. R. \& Ruschel, E. (2009). A meritocracia na política educacional brasileira (1930-2000). Revista Portuguesa de Educação, 22(1), 179-206. Recuperado de

http://www.scielo.mec.pt/scielo.php?script $=$ sci_abstract\&pid=S0871$91872009000100008 \& \operatorname{lng}=$ pt\&nrm=iss.

Valle, I. R. (2013). (In)Justiça escolar: estaria em xeque a concepção clássica de democratização da educação?. Educ. Pesqui., 39(3), 1-13. Recuperado de http://www.scielo.br/pdf/ep/2013nahead/ao p1147.pdf.

Vergès, P. (1992). Programas informáticos para análise de semelhanças e evocações. Aix en Provence: LAMES-CNRS.

Vergès, P., \& Guimelli, C. (1994). Approche du noyau central: propriétés quantitatives et structurales. In C. Guimelli (orgs.). Structures et transformations des représentations sociales. França: Delachaux et Niestlé.

Wachelke, J. F. R., \& Wolter, R. P. (2011). Critérios de construção e relato da análise prototípica para representações sociais. Psicologia: Teoria e Pesquisa, 27,521-526. doi: 10.1590/S010237722011000400017.

Wolter, R. P., Gurrieri, C., \& Sorribas, E. (2009). Empirical illustration of the hierarchical organisation of social thought: a domino effect?. Interamerican Journal of Psychology, 43, 1-11.

Wolter, R. P., Wachelke, J. F. R. (2013). Índices de distribuição de evocações: Raridade, diversidade e comunidade de corpora de representações sociais. Revista de Psicologia: Teoria e Prática, 15, 119129.

Wolter, R. P., Wachelke, J. F. R., \& Naiff, D. (2016). A abordagem estrutural das representações sociais e o modelo dos esquemas cognitivos de base: perspectivas teóricas e utilização empírica. Temas em Psicologia, 24(3), 1139-1152. doi:10.9788/TP2016.3-18. 


\section{Dados sobre os autores:}

- Álvaro Rafael Santana Peixoto: Possui graduação em Psicologia pela Universidade do Estado do Rio de Janeiro - UERJ (2017), tendo realizado pesquisas relacionadas ao tema Cotas e Religiões de Matriz Africana. Mestrando em Psicologia Social pelo Programa de PósGraduação em Psicologia Social da UERJ, onde realiza pesquisa acerca da Estratificação Social e de que forma esse fator influencia no Pensamento Social de Jovens Estudantes da Rede Estadual do Rio de Janeiro.

- Thamiris Marques da Silva: Possui graduação em Psicologia (2014), Mestrado (2016) e Doutorado (em andamento) em Psicologia Social pela UERJ. Atualmente é Professora Substituta do Departamento de Fundamentos em Psicologia do Instituto de Psicologia da UERJ.

- Rafael Moura Coelho Pecly Wolter: Possui graduação em Psicologia pela Universidade de Paris V (René Descartes) (2004) e Master Recherche em Psicologia Social pela mesma instituição (2005). Durante o doutorado foi professor nas universidades de Paris V (René Descartes), Versailles Saint-Quentin e Amiens. Defendeu a tese de doutorado (Pensée sociale et situations de crise: le rôle des nexus dans l'implication personnelle et les modes de raisonnement), sendo orientado pelo Professor Michel-Louis Rouquette. Após um estágio de pós-doutorado na UERJ, financiado pela FAPERJ, junto ao Professor Celso Pereira de Sá, tornou-se Professor do Instituto de Psicologia e do Programa de Pós-Graduação em Psicologia Social da UERJ e da Universidade Salgado de Oliveira.

\section{Agência de Fomento:}

Fundação Carlos Chagas Filho de Amparo à Pesquisa do Estado do Rio de Janeiro e Conselho Nacional de Desenvolvimento Científico e Tecnológico 